\title{
Sudden Death in a Case of Isolated Hydatid Cyst of Lung -A Case Report
}

\author{
Dr. Sayak Sovan Dutta ${ }^{1}$, Dr.SandipMukhopadhyay ${ }^{2}$, Dr.KausikTudu $^{3}$, \\ ${ }^{I}$ Demonstrator, Deptt of FSM, NRS Medical College, Kolkata \\ ${ }^{2}$ Demonstrator, Deptt of FSM, NRS Medical College, Kolkata \\ ${ }^{3} 3^{\text {rd }}$ year PGT, Deptt of FSM, NRS Medical College, Kolkata
}

\begin{abstract}
Death is said to be sudden or unexpected when a person not known to have been suffering from any dangerous disease, injury or poisoning is found dead or dies within 24 hours after the onset of terminal illness (WHO). According to some authors, sudden deaths as those occurring within 6 hours of last illness.In view of modern diagnostic tools available, Sudden death are those occurs instantaneously or within one hourof onset of symptoms. Unexpected character of death, rather than suddenness of death is important. The incidence is approximately $10 \%$ of all deaths. Sudden death May be due to- (a) Natural Causes(b) Unnatural Causes.Natural cause of deathmeansthe death was caused entirely by the disease, and the trauma or poison did not play any part in bringing it about.Causes may be due to (I) Diseases of the Cardiovascular System (45 to 50\%) (II) Respiratory System (15 to 23\%) (III) Central Nervous System (10 to 18\%) (IV) Alimentary System (6 to 8\%) (V) Genito-urinary System (3 to 5\%)(VI) Miscellaneous (5 to lo\%). Negative Autopsy may appear in sudden natural death cases due to (a) Cardiac Arrest(b) Neurogenic shock / Vasovagal attack(c)Epileptic fit(d) Anaphylaxis(e) Hypoglycaemic shock(f) Electrolyte derangements. Here in the following case a 7 year old boy died with 2 hours after one episode of vomiting, where autopsy was suggestive of ruptured hydatid cyst of left lung which was further confirmed by Histopathological examination. No deposits were detected in other organs, suggestive of a primary alveolar Echinococcosis which is extremely rare in the sense that most of the cases lung deposit is secondary to liver being the primary one.
\end{abstract}

Keywords: sudden death, negative autopsy hydatid cyst, Echinococcosis

\section{Introduction}

History of the case as per information furnished by Police: On 15.11.15, between 11.00 hours to 11.30 hours, while playing at home, a 7 year old boy suddenly became unconscious following one episode of vomiting.He was immediately shifted to a nearby Nursing Home from where he was again shifted to another Nursing Home at 12:00 hours. Lastly he was shifted to Tertiary Care Hospital where he was declared brought dead on the same day at 12.57 hrs. Post mortem examination done on 16.11.2015 at 14:00 hours at NRS Medical College Hospital Morgue.

\section{Postmortem examination:}

\section{A. External Findings}

A male subject of 7 years age.Length was 3 feet 10 inches. Built was average, weighing $26 \mathrm{~kg}$ and moderately nourished.Scalp hair was 2 inch long, black in color. Beard \& moustache not appeared. Rigor mortis was detectedall over the body (cool chamber). Eyes were closed and corneas were hazy. Post mortem stain present over dependant part of body at back except over pressure points showing contact pallor and flattening. Bluish discoloration of finger nails and lips detected.Wearing apparels: blue colored half sleeves tee shirt and blue colored half pant.No external injury could be detected even after careful examination.

\section{B. Internal Examination on Dissection:}

Scalp was Healthy, Skull and Vertebrae were intact, Membrane was congested. Brain was congested and oedematous. Thorax: Walls -healthy, Ribs and Cartilage were intact, Pleurae - Congested, few petechial haemorrhagic spots detected on visceral surface of pleurae.Larynx and Trachea - Mucous membrane was Congested.Oedema of epiglottis and trachea detected. Hyoid bone and thyroid cartilage were intact.

Right Lung. - Wt-142gm, congested and oedematous

Left Lung. - Wt-185gm, Congested, collapsed. A well defined almost oval ruptured cyst detected at posterior basal segment of left lung measuring 6" $\mathrm{x} 4$ ", with grain like materials inside, surrounded by a dense, white, fibrous capsule with a tear of 1.5 " $\mathrm{x} 1$ "' $\mathrm{x}$ cavity on its surface and some grain like substances found in left pleural cavity. 


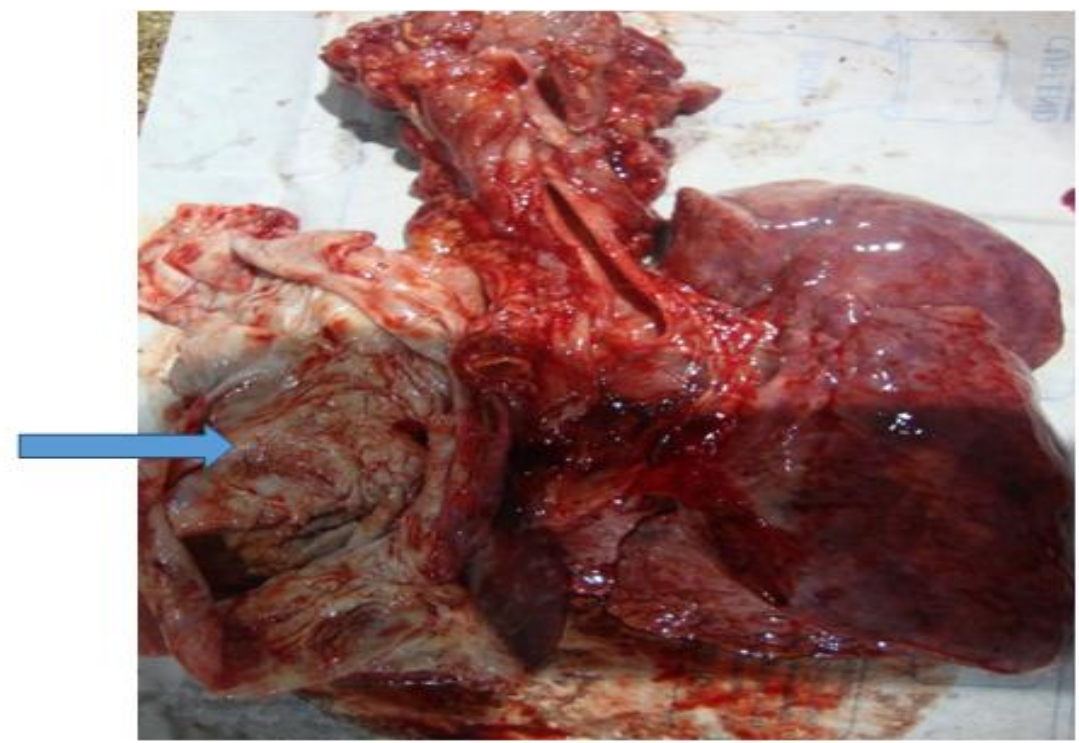

Fig 1: back of both lung showing ruptured cyst at posterior aspect of left lung marked with arrow

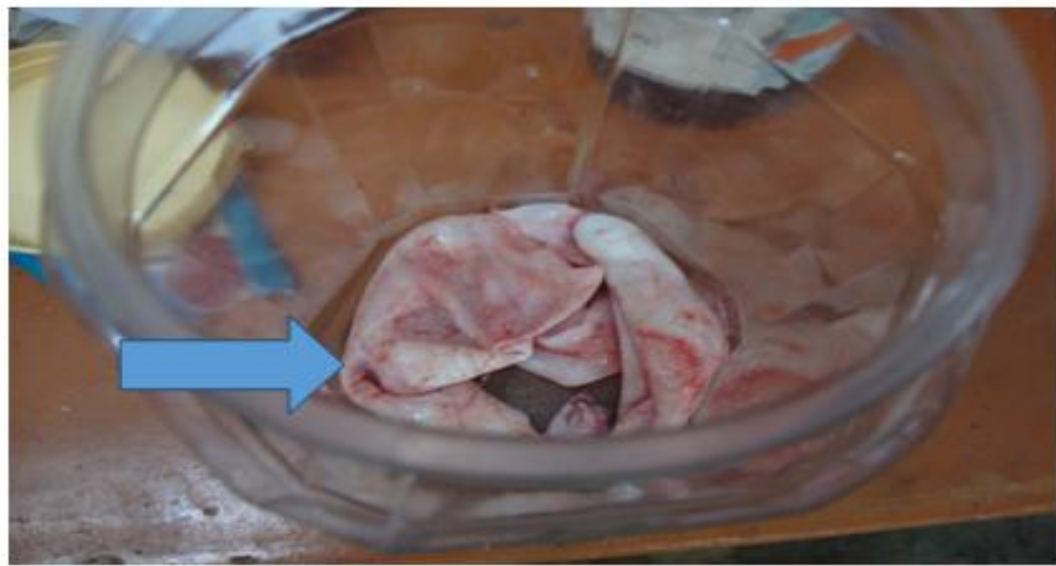

Fig 2: resected cyst wall

Heart: Wt - 69 gm, healthy \& no obvious abnormality detected. Vessels were Healthy

Abdomen:Stomach and its contents - Whole Wt. - 232gm.content: partly digested food, 130gm.

No untoward smell. Mucous membrane was congested.

Small and Large intestine - Mucous membrane - congested, contain gas and faeces

Liver - Wt. - 522gm ,Congested

\section{No abnormality detected to any organ}

- Materials preserved

1) Stomach with its content, proximal $30 \mathrm{~cm}$ of small intestine, longitudinal half of each kidney, $500 \mathrm{gm}$ of liver with gall bladder - preserved in saturated solution of common salt with control,

2) Blood without any preservatives,

3) Blood soaked in blotting paper with control,

4) Wearing Apparel

1-4 -duly packed, labeled, sealed and signed and handed over to the escorting police personal for sending those for chemical examination to State FSL through local PS.

5) left lung with white fibrous capsule,6) Tissues from liver, kidneys, brain, heart, spleen - preserved in $10 \%$ formal saline with control- duly packed, labeled, sealed and signed and handed over to the escorting police personal for sending for Histopathological examination to Dept. of Pathology of any State Govt Medical College. Cause of death was opined:Death was due to the effects of rupture of hydatid cyst of lung as noted above, ante mortem in nature. Histopathology report revealed Laminated membraneof hydatid cyst in the lung with scolices and presence of hooklets. Though no deposits were detected in other organs especially in liver suggested that it was a case of isolated primary alveolar Echinococcosis which is extremely rare. 


\section{Discussion}

Cystic Echinococcosis is a zoonotic infection which is caused by the helminthic parasite dog tapeworm EchinococcusGranulosus. Dog and other canines are definitive host - adult worm lives in their small intestine and they discharge large no. of eggs in faeces. Goat, sheep, cattle, pig, horse and man are intermediate host larval stage passed within these animals through ingestion, while grazing in the field Infection generally acquired in childhood by -

(a) Direct contact (during intimate handling and fondling, hands get contaminated with faeces),

(b) By allowing dog to feed from same dish,

(c) By taking uncooked vegetables contaminated with infected canine faeces.

- In duodenum - embryos hatched out - after few hours bore through intestinal wall - enter portal circulation - liver acts as $1^{\text {st }}$ filter - few pass - enter pulmonary circulation - lungs act as $2^{\text {nd }}$ filter -few pass - enter general blood stream - lodge in various organ

- Wherever the embryo settles, forms into hydatid cyst

\section{Cyst wall hastwo layers -}

(1) Outer Cuticular Layer (ectocyst) : laminated hyaline membrane, up to $1 \mathrm{~mm}$ thickness ,to the naked eye,

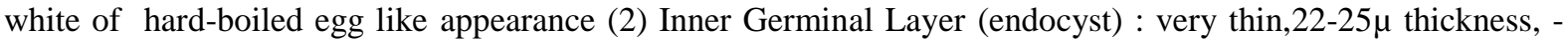
contains brood capsules with scolices, secretes hydatid fluid

- In majority, subjects remain symptomless for life but in some, symptoms may develop due to pressure effects and in very rare case, it ruptures

- Hydatid fluid - clear, colourless, slightly acidic, contain $\mathrm{NaCl}, \mathrm{NaSO} 4$, sodium phosphate, sodium and calcium salts of succinic acid \&hydatid sand (liberated brood capsule, free scolices and loose hooklets) highly toxic, when absorbed after rupture of cyst, gives rise to anaphylactic shock .

\section{Conclusion}

The patient had no documented H/o epilepsy, chest pain, respiratory distress on exertion like playing or abdominal pain. But his parents give history of fondness of the deceased towards a local street dog few years back - those kinds of dogs are generally not dewormed - highly infectious. During autopsy, left lung found congested, collapsed and on its posterior basal segment hydatid cyst found ruptured with grain like material within cyst cavity and left plural cavity. Histopathological examination confirmed hydatid cyst wall with no deposits in any other organs especially in liver establishing it as a case of Primary alveolar Echinococcosis.

\section{References}

[1]. www.forensicpathologyonline.com/e-book/autopsy/sudden-deaths

[2]. Reddy, K. S. Narayan, The Essentials Of Forensic Medicine And Toxicology, $34^{\text {th }}$ Edition, p. 150

[3]. Agarwal Anil,Textbook Of Forensic Medicine and Toxicology, $1^{\text {st }}$ edition,p. 170

[4]. Biswas, Gautam, Review Of Forensic Medicine And Toxicology, $3^{\text {rd }}$ edition, p. 131

[5]. Chatterjee, K.D.,Parasitology, $12^{\text {th }}$ edition,p.107-132

[6]. en.wikipedia.org/wiki/Echinococcosis

[7]. Jedidi M1, Mlayeh S, Masmoudi T, Souguir MK, Zemni M., Sudden death due to hydatid cyst: thirty-four medicolegal autopsy cases, J Forensic Sci. 2006 Mar;51(2):400-2. 